\title{
An unusual case of Bravo capsule aspiration
}
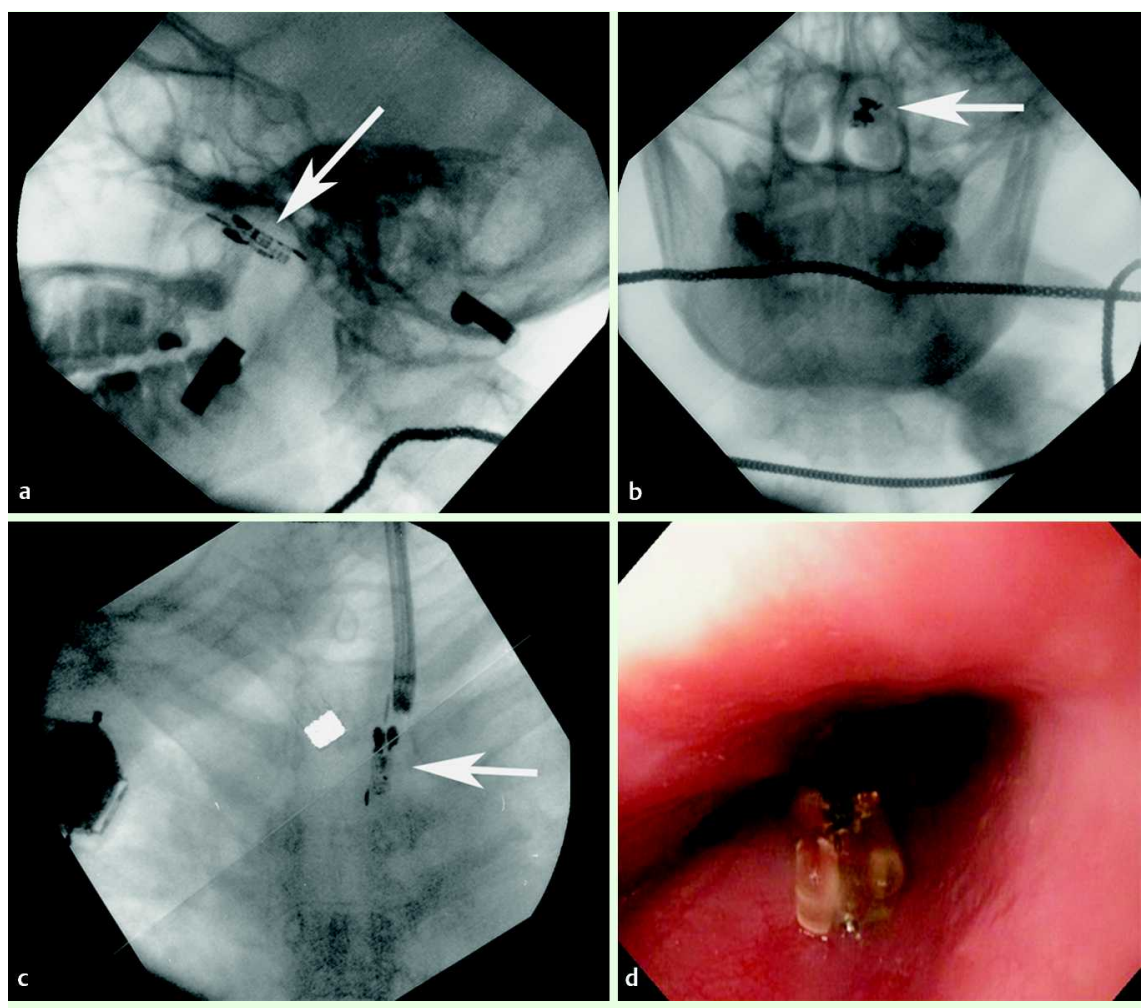

Fig. 1 The Bravo capsule was finally detected in the patient's nasopharynx using roentgenoscopy $(\mathbf{a}, \mathbf{b})$. Removal through the nostril was not possible and the capsule was pushed through the esophagus into the stomach using a $5.8 \mathrm{~mm}$ endoscope (c, d).

Prolonged intraesophageal pH monitoring represents the gold standard for the diagnosis of gastroesophageal reflux disease (GERD). The Bravo pH Testing System (Medtronic Inc., Shoreview, Minnesota, USA) allows intraesophageal $\mathrm{pH}$ monitoring by placement of a capsule on the esophageal mucosal wall. No catheter is used and therefore the system is more likely to show greater patient tolerability [1]. Capsule endoscopy is generally a safe and well-tolerated procedure with few complications. Clinically significant complications, including symptomatic capsule retention and aspiration, occur in less than $2 \%$ of examinations [2].

A 44-year-old patient was referred to our institution for Bravo capsule $\mathrm{pH}$ metry for evaluation of atypical GERD symptoms. The patient was sedated using continuous intravenous propofol before passing the transnasal indwelling delivery catheter. Subsequently the Bravo capsule was placed $5 \mathrm{~cm}$ above the upper margin of the previous manometrically determined lower esophageal sphincter. The capsule was released after the application of $510 \mathrm{~mm} \mathrm{Hg}$ of suction for 20 seconds.

Directly after deployment the sedated patient started to retch and subsequently to cough heavily. Oxygen saturation dropped to $74 \%$. Sedation was immediately stopped. Consciousness was regained afterwards and oxygen saturation returned to normal. Endoscopy was performed but the capsule was found neither in the esophagus nor the stomach. Roentgenoscopy was performed but the capsule could not be found within the abdominal or thoracic organs. During further examination the Bravo capsule was detected in the nasopharynx (ه Fig. 1 a,b). We assume that the capsule was aspirated at first into the lungs and afterwards coughed up into the nasopharynx. Removal through the nostril or mouth was not possible. Therefore, the capsule was pushed through the esophagus into the stomach using a transnasal $5.8 \mathrm{~mm}$ video-endoscope ( $\bullet$ Fig. 1 c, d), and subsequently extracted by means of a grasping forceps.
D. von Renteln ${ }^{1}$, T. Kayser ${ }^{1}$, B. Riecken ${ }^{1}$, K. Caca ${ }^{1}$

Department of Gastroenterology, Hepatology, and Oncology, Klinikum Ludwigsburg, Ludwigsburg, Germany

\section{References}

1 Marchese M, Spada C, Iacopini F et al. Nonendoscopic transnasal placement of a wireless capsule for esophageal $\mathrm{pH}$ monitoring: feasibility, safety, and efficacy of a manometry-guided procedure. Endoscopy 2006; 38: $813-818$

2 Ho KK, Joyce AM. Complications of capsule endoscopy. Gastrointest Endosc Clin N Am 2007; 17: $169-178$

Bibliography

DOI 10.1055/s-2007-995804

Endoscopy 2008; 40: E174

(c) Georg Thieme Verlag KG Stuttgart · New York . ISSN 0013-726X

Corresponding author

\section{K. Caca, MD}

Department of Gastroenterology, Hepatology, and Oncology

Klinikum Ludwigsburg

Teaching Hospital of the University Heidelberg Ludwigsburg

Germany

Fax: +49-7141-9967219

karel.caca@kliniken-lb.de 